\title{
Effect of Mentha longifolia on FSH Serum Level in Premature Ovarian Failure
}

\author{
Roshanak Mokaberinejad1', Elham Akhtari², Mojgan Tansaz ${ }^{*}$, Soodabeh Bioos², \\ Mohammad Kamalinejad ${ }^{3}$, Nafiseh Zafarghandi ${ }^{4}$, Ali Ghobadi ${ }^{5}$, \\ Farnaz Sohrabvand6, Ali Akhbari ${ }^{7}$ \\ ${ }^{1}$ School of Traditional Medicine, Shahid Beheshti University of Medical Sciences, Tehran, Iran \\ ${ }^{2}$ Faculty of Traditional Medicine, Tehran University of Medical Sciences, Tehran, Iran \\ ${ }^{3}$ Department of Pharmacognosy, School of Pharmacy, Shahid Beheshti University of Medical Sciences, Tehran, \\ Iran \\ ${ }^{4}$ Department of Gynecology and Obstetrics, Faculty of Medical Sciences, Shahed University, Tehran, Iran \\ ${ }^{5}$ Department of Traditional Pharmacy, Faculty of Traditional Medicine, Tehran University of Medical Sciences, \\ Tehran, Iran \\ ${ }^{6}$ Infertility Department of Vali-e-Asr Hospital, Emam Khomeini Hospital Complex, Tehran University of Medical \\ Sciences, Tehran, Iran \\ ${ }^{7}$ Ashrafi Esfahani Hospital, Shahid Beheshti University of Medical Sciences, Tehran, Iran \\ Email: ${ }^{*}$ tansaz mojgan@yahoo.com
}

Received 22 February 2014; revised 20 March 2014; accepted 27 March 2014

Copyright (C) 2014 by authors and Scientific Research Publishing Inc.

This work is licensed under the Creative Commons Attribution International License (CC BY).

http://creativecommons.org/licenses/by/4.0/

c) (i) Open Access

\section{Abstract}

Purpose: Premature ovarian failure (POF) includes cessation of normal ovarian function before age 40, causing amenorrhea, menopausal symptoms and general health problems. Hormone replacement therapy (HRT) can be administered in order to prevent menopausal symptoms, osteoporosis and vascular complications. Due to the contraindications and side effects of HRT and the increasing demand for alternative therapeutic modalities, we used Mentha longifolia, which is known in the Iranian traditional medicine (ITM), as being able to cause menstrual bleeding in women with early amenorrhea and decreased FSH serum. Methods: In this pilot study, we report twenty seven amenorrheic women with POF who were referred to the Iranian traditional medicine clinic in Tehran and treated by Mentha longifolia. All those patients had high FSH levels and amenorrhea. They were in their fertility age, between 30 to 40 years old. They were asked to take a cup of herbal tea which was steeped with Mentha longifolia tea three times a day for 2 weeks in 3 menstural cycles. If the patients developed menstruation, the FSH serum level was

\footnotetext{
${ }^{*}$ Corresponding author.
}

How to cite this paper: Mokaberinejad, R., Akhtari, E., Tansaz, M., Bioos, S., Kamalinejad, M., Zafarghandi, N., Ghobadi, A., Sohrabvand, F. and Akhbari, A. (2014) Effect of Mentha longifolia on FSH Serum Level in Premature Ovarian Failure. Open Journal of Obstetrics and Gynecology, 4, 356-360. http://dx.doi.org/10.4236/ojog.2014.47053 
measured immediately; otherwise they had an FSH measurement one month after the beginning of therapy. Results: Mean age of patients was 36.44 \pm 1.5 years. Mean FSH level before treatment was $79.13 \pm 19.17 \mathrm{mIU} / \mathrm{ml}$, and after treatment was $27.83 \pm 16.14$ $\mathrm{mIU} / \mathrm{ml}$. In four patients who did not have any response, mean range of FSH was $82.37 \pm$ $19.75 \mathrm{mIU} / \mathrm{ml}$ before treatment and afterwards it was $81.97 \pm 21.52 \mathrm{mIU} / \mathrm{ml}$. After treatment with herbal teas, there was a significant decrease in FSH $(79.39 \pm 19.17$ to $27.83 \pm$ $16.14 \mathrm{mIU} / \mathrm{ml}$, p value $<0.001)$. All patient except four $(14.81 \%)$ had mensturation after taking the herbal medicine. Those four patients showed no decrease in FSH level. More of the patients who used medicinal tea achieved regular monthly bleeding when followed for three cycles.

\section{Keywords}

Amenorrhea, FSH, Iranian Traditional Medicine, Mentha longifolia, Premature Ovarian Failure, POF

\section{Introduction}

Premature ovarian failure (POF) generally describes a syndrome consisting of amenorrhea, estrogen deficiency and elevated/menopausal levels of gonadotropins in women age below 40. POF can be primary (spontaneous POF) or secondary (induced by radiation, chemotherapy or surgery). Based on existing evidence, the majority of POF cases are of unknown etiology (Goswami and Conway 2007; Vujovic 2009) [1]. There is evidence that POF often affects the quality of life in women and they consider it as a shocking development which leaves most of them feeling "out of synchrony" in their lives (Groff et al. 2005) [2]. Women with POF have been reported to have a 50\% higher mortality rate than women with menopause at age 52 - 55 (Maclaran et al. 2010) [3]. POF is also associated with significant morbidity due to lower life expectancy and higher incidence of cardiovascular disease, osteoporosis, psychological problems, sexual dysfunction and sub fertility (Maclaran et al. 2010) [3].

Therapeutic options include empiric hormone replacement with estrogen and progesterone (Lieman and Santoro 1997) [4]. Hormone replacement therapy (HRT) should be administered in order to avoid menopausal symptoms, osteoporosis and vascular diseases (Armitage et al. 2003; Christin-Maitre and Braham 2008) [5] [6].

The reporting of data from the Women's Health Initiative (WHI) and Million Women Studies (MWS) has shown the growing population of young women who have suffered POF. 37\% of women with POF considered stopping HRT due to reasons such as fear of developing breast cancer following the original WHI/MWS reports (Nick Panay and Kalu 2009) [7].

There is evidence that replacement with bio-identical hormones, i.e., natural estrogen and progesterone, may be associated with a lower risk of breast cancer and thrombosis (Nick Panay and Kalu 2009) [7].

There is not a good understanding about the pathophysiology, natural history, psychosocial effects, medical and psychosocial management of primary ovarian insufficiency (Cooper et al. 2011) [8].

There is unmet need to identify etiology, possible prevention and therapeutic options (Vujovic 2009) [9].

The concepts of menstruation and its mechanisms have been known in the Iranian traditional medicine (ITM), and administration of medicinal herbs has been used as a therapeutic intervention. Based on Iranian traditional medicine texts particularly Canon of Medicine (Avicenna 980-1037 A.D.) [10] and Al-Havi (Rhazes 865-925 A.D.) [11], Mentha longifolia is one of the medicinal herbs that can affect menstrual periods (Ibn Sina 2005; Razi 2010; Emtiazy et al. 2012) [10]-[12].

Mentha longifolia (L.) Huds, a member of the Lamiacea family (Labiatae), originates from South east Asia and is known as Horse mint or wild mint (Okoh and Afolayan 2011) [13]. The historical use of Horse mint is not different from its use in modern herbal medicine. It is usually used as a remedy for common cold, cough, sinusitis, fever, bronchitis, nausea, vomiting, indigestion, intestinal colic and loss of appetite; however its efficacy in menstrual disorders is not known in modern medicine. M. longifolia known as Fudanaj and Poneh in ITM is a common constituent of the Middle Eastern dishes (Naghibi et al. 2009) [14]. 
Based on our best of knowledge this is the first pilot study to test the effect of Mentha longifolia in women with POF.

\section{Materials and Methods}

\subsection{Patients}

Twenty Seven women were seen at the Iranian traditional medicine outpatient clinic with chief complaint of amenorrhea. They had elevated FSH levels in two occasions. All of them qualified for the diagnosis of POF. All of them were in their fertility period with ages between 30 - 40 years old.

The study was opened after approval by the Institutional review Board (IRB) of the Tehran University of Medical sciences and Shahid Beheshti University of medical Sciences; and all the entered the study after receiving enough explanation about the study and signing an onset form approved by IRB.

Patients were asked to take a cup $(250 \mathrm{ml}$ ) of herbal tea which was steeped with Mentha longifolia tea (\% 8 $\mathrm{g} / \mathrm{L}$ ) three times a day for 2 weeks. The patients had to report any signs of bleeding immediately to research team. If they developed menstrual bleeding during the therapy period, their serum FSH was measured. Those patients who did not develop any menstrual bleeding, their FSH level was tested after one month from the time starting the tea. All patients were followed for three cycles.

\subsection{Preparations of Herbal Teas}

The herbal tea was made by pouring a cup $(250 \mathrm{~mL}$ ) of boiling water over 1 heaped tablespoons U.S. (2 g) of the dried leaves and steeping for 5 to $10 \mathrm{~min}$. All teas were prepared fresh.

\subsection{Mentha longifolia (L.) Huds Preparation}

Mentha longifolia (L.) Huds dried leaves were obtained commercially from a licensed dispenser in Tehran city, the center of Tehran province, Iran which was identified by Professor Gh Amin, a botanical taxonomist at faculty of pharmacy, Tehran University of Medicinal Science. PMP number is 308.

\section{Analysis of Mentha longifolia}

Dried plant was used for extraction of total essential oil using Clevenger apparatus and yielded $1 \mathrm{ml} / 100 \mathrm{mg}$ of dried plant. Analysis of total essential oil showed some major component as: 1, 8 cineole (11.58\%), piperitone oxide (42.51\%) and caryophyllene oxide (3.64\%).

\subsection{Biochemical Examinations}

Blood samples were taken from all patients for evaluating the hormonal status including FSH, LH, TSH and prolactin serum levels before starting them on medicinal tea and afterwards as described. The blood samples (10 $\mathrm{mL}$ ) were collected from each of the patients after a $12 \mathrm{~h}$ overnight fasting. The blood was separated by centrifugation at $3000 \mathrm{rpm}$ for $10 \mathrm{~min}$ after standing at room temperature for $15 \mathrm{~min}$. Luteinizing hormone (LH), Follicle-stimulating hormone (FSH) were measured by using the Roch diagnostics ${ }^{\circledR}$ chemiluminescence Immunoassay (CIA) analyzer.

\subsection{Statistical Analysis}

The data is presented as the mean \pm SD. Statistical significance was tested by paired-t test. A probability value of less than $0.05(\mathrm{p}<0.05)$ was considered as statistically significant.

\section{Results}

Twenty Seven patients who were seen at the Iranian traditional medicine outpatient clinic with the chief complaint of amenorrhea with at least two occasions of elevated FSH levels were included in this pilot study. All of them were diagnosed as having POF. All patients were in their fertility period, with ages between $30-40$ years old.

Mean age of the patients was $36.44 \pm 1.5$ years, with an average $1.90 \pm 0.9$ years period of menstrual irregu- 
larity and amenorrhea of $4.8 \pm 1.7$ months. The average range of FSH before treatment was $79.39 \pm 19.17$ $\mathrm{mIU} / \mathrm{mL}$.

After 2 weeks of the treatment for 3 cycles, there was a significant decrease in FSH (from 79.39 \pm 19.17 to $27.83 \pm 16.14 \mathrm{mIU} / \mathrm{ml}$, p value $<0.001)$. All patients except four $(14.81 \%)$ had menstrual bleeding on average 19.2 days after taking the medication. Those patients showed also no decrease in FSH level. One of those patients had very abnormal bleeding. In the non-responders, mean range of FSH was $82.37 \pm 19.75$ before treatment and after it was $81.97 \pm 21.52$.

\section{Discussion}

The impact of POF on the patients' quality of life is profound (Tansaz et al.) [15], and it has various aspects, ranging from psychological devastation to multi-system effects of estrogen deprivation and their sequel. POF may in fact represent an acceleration of the aging process (Pal and Santoro 2002) [16].

Estrogen replacement is recommended in POF to alleviate symptoms and protect against bone loss and cardiovascular diseases (Cartwright et al. 2010) [17].

The absence of evidence-based guidelines regarding the ideal hormone replacement strategy for young women with POF raises a clear challenge (Nick Panay and Kalu 2009) [7].

There is evidence that the degenerative changes noted in those patients; however, they are not totally ameliorated with estrogen replacement (Pal and Santoro 2002) [16].

Serious complications such as thrombosis and breast cancer due to HRT have been reported (Nick Panay and Kalu 2009) [7]. There is an increasing number of women who prefer to have alternative therapies rather than HRT, and this is getting more attention by healthcare industry. Women want to know about those therapeutic modalities which may be available over the counter rather than by prescription; so it is important that health professionals are able to provide women with useful information in order to support them to make informed and educated decisions about management of menopause effectively and safely (N. Panay 2011) [7].

It has been known an ITM teachings and textbooks that Horse mint can cause menstrual bleeding in women with amenorrhea (Mokaberinejad et al. 2012) [18] (Ibn Sina 2005) [10]. However, its effect on POF has not been scientifically evaluated yet.

In this pilot study, we observed that after using Horse mint tea in women with POF, menstrual bleeding occured and FSH level decreased significantly.

Mokaberinejad et al. studied the effects of Mentha longifolia (L.) in women with amenorrhea in reproductive age (except early Menopause). In their trial it was showed that the consumption of syrup from Mentha longifolia (L.) in addition to causing menstrual period in amenorrhic women was effective in reducing LH serum in woman with polycystic ovary syndrome (Mokaberinejad and et al. 2012) [18].

In a study by Shariati M. et al., the effect of Lamiacea family on FSH was investigated. Assessment of the effect of Mentha pulegium leaves on gonadotropin tests in male rat showed that the hydro-alcoholic extract of Mentha pulegium leaves causes a significant decrease of FSH and LH levels (shariati et al. 2011) [19].

In another experimental study by Akdogan M. et al. on effects of Mentha piperita and Mentha spicata on FSH and LH levels, it was shown that the consumption of $M$. piperita and M. spicata can increase the levels of FSH and LH in rats (Akdogan et al. 2004) [20].

It has been hypothesized that treatment with some herbal medicines could result in decrements in FSH. These preliminary results suggest that Mentha longifolia can be considered as an alternative therapeutic modality for the management of POF.

We know that the impact of POF on patients is profound, with numerous aspects, ranging from psychological devastation to multi-system effects of estrogen deprivation and their sequel. POF may in fact represent an acceleration of the aging process.

Therefore, further research to examine the feasibility of Mentha longifolia as a therapy for POF is strongly recommended. A well designed clinical trial is needed to identify the appropriate dosage for Mentha longifolia to exert its effects on resumption and regularity of menstruation and reduction of serum FSH levels.

\section{Acknowledgements}

The authors gratefully acknowledge the help of Dr. Hamed hosseini MD, MPH, PHD candidate, school of public health, Tehran university of Medical Sciences. 


\section{References}

[1] Goswami, D. and Conway, G.S. (2007) Premature Ovarian Failure. Hormone Research in Paediatrics, 68, $196-202$. http://dx.doi.org/10.1159/000102537

[2] Allison, A. G., et al. (2005) Assessing the Emotional Needs of Women with Spontaneous Premature Ovarian Failure. Fertility and Sterility, 83, 1734-1741. http://dx.doi.org/10.1016/j.fertnstert.2004.11.067

[3] Maclaran, K., Horner, E. and Panay, N. (2010) Premature Ovarian Failure: Long-Term Sequelae. Menopause International, 16, 38-41. http://dx.doi.org/10.1258/mi.2010.010014

[4] Lieman, H. and Santoro, N. (1997) Premature Ovarian Failure: A Modern Approach to Diagnosis and Treatment. The Endocrinologist, 7, 314. http://dx.doi.org/10.1097/00019616-199707050-00006

[5] Armitage, M., Nooney, J. and Evans, S. (2003) Recent Concerns Surrounding HRT. Clinical Endocrinology, 5, 145-155. http://dx.doi.org/10.1046/j.1365-2265.2003.01815.x

[6] Christin-Maitre, S. and Braham, R. (2008) General Mechanisms of Premature Ovarian Failure and Clinical Check-Up. Gynécologie Obstétrique \& Fertilité, 36, 857-861. http://dx.doi.org/10.1016/j.gyobfe.2008.07.003

[7] Nick, P. and Emmanuel, K. (2009) Management of Premature Ovarian Failure. Best Practice \& Research Clinical Obstetrics \& Gynaecology, 23, 129-140. http://dx.doi.org/10.1016/j.bpobgyn.2008.10.008

[8] Cooper, A.R., et al. (2011) The Time Is Now for a New Approach to Primary Ovarian Insufficiency. Fertility and Sterility, 95, 1890-1897. http://dx.doi.org/10.1016/j.fertnstert.2010.01.016

[9] Vujovic, S. (2009) Aetiology of Premature Ovarian Failure. Menopause International, 15, 72-77. http://dx.doi.org/10.1258/mi.2009.009020

[10] Sina, I. and Hussein, A.A. (2005) Medicine. In: Shams al-Din, I., Ed., Al-Qanon fi al-Tibb. Alamy Le-Al-Matbooat institute, Lebanon.

[11] Razi, M.I.Z. (2010) Medicine. In: Al-madkhal elaa sanaate al-teb, Ed., Alhavi. The Institute for Medical History-Islamic and Complementary Medicine, Tehran University of Medical Sciences, Tehran.

[12] Emtiazy, M., et al. (2012) Atheroprotector Role of the Spleen Based on the Teaching of Avicenna (Ibn Sina). International Journal of Cardiology.

[13] Okoh, O.O. and Afolayan, A.J. (2011) The Effects of Hydrodistillation and Solvent Free Microwave Extraction Methods on the Chemical Composition and Toxicity of Essential Oils from the Leaves of Mentha longifolia L. Subsp. Capensis. African Journal of Pharmacy and Pharmacology, 5, 2474-2478.

[14] Naghibi, F., et al. (2009) Labiatae Family in Folk Medicine in Iran: From Ethnobotany to Pharmacology. Iranian Journal of Pharmaceutical Research, 4, 63-79.

[15] Tansaz, M., Mokaberinejad, R., Bioos, S., Sohrabvand, F. and Emtiazy, M. (2013) Avicenna Aspect of Premature Ovarian Failure. Iranian Journal of Reproductive Medicine, 11, 167-168.

[16] Pal, L. and Santoro, N. (2002) Premature Ovarian Failure (POF): Discordance between Somatic and Reproductive Aging. Ageing Research Reviews, 1, 413-423. http://dx.doi.org/10.1016/S1568-1637(02)00009-0

[17] Cartwright, B., Robinson, J. and Rymer, J. (2010) Treatment of Premature Ovarian Failure Trial: Description of an Ongoing Clinical Trial. Menopause International, 16, 18-22. http://dx.doi.org/10.1258/mi.2010.010010

[18] Mokaberinejad, R., Zafaghandi, N., Bioos, S., et al. (2012) Mentha longifolia Syrup in Secondary Amenorrhea: A Double-Blind, Placebo-Controlled, Randomized Trials. DARU Journal of Pharmaceutical Sciences, 20, 97.

[19] Shariati, M., Esfandiari, A., Modarresi, M. and Rahmani, Z. (2011) Antifertility Effect of Hydro-Alcholic Extract of Mentha pulegium Leaves in Adult Male Rats. Journal of Sabzevar University of Medical Science, 19, 34-41.

[20] Akdogan, M., Ozguner, M., Kocak, A., Oncu, M. and Cicek, E. (2004) Effects of Peppermint Teas on Plasma Testosterone, Follicle-Stimulating Hormone, and Luteinizing Hormone Levels and Testicular Tissue in Rats. Urology, 64, 394-398. http://dx.doi.org/10.1016/j.urology.2004.03.046 